\title{
Targeting tissue-specific metabolic signaling pathways in aging: the promise and limitations
}

\author{
Fang Hu, Feng Liu ${ }^{凶}$ \\ Metabolic Syndrome Research Center, The Second Xiangya Hospital of Central South University, Changsha 410011, China \\ $\square$ Correspondence: liuf@hotmail.com (F. Liu)
}

Received August 27, 2013 Accepted September 11, 2013

\begin{abstract}
It has been well established that most of the age-related diseases such as insulin resistance, type 2 diabetes, hypertension, cardiovascular disease, osteoporosis, and atherosclerosis are all closely related to metabolic dysfunction. On the other hand, interventions on metabolism such as calorie restriction or genetic manipulations of key metabolic signaling pathways such as the insulin and mTOR signaling pathways slow down the aging process and improve healthy aging. These findings raise an important question as to whether improving energy homeostasis by targeting certain metabolic signaling pathways in specific tissues could be an effective antiaging strategy. With a more comprehensive understanding of the tissue-specific roles of distinct metabolic signaling pathways controlling energy homeostasis and the crosstalks between these pathways during aging may lead to the development of more effective therapeutic interventions not only for metabolic dysfunction but also for aging.
\end{abstract}

KEYWORDS aging, metabolic disease, insulin, mTOR, caloric restriction

\section{INTRODUCTION}

The normal process of aging is associated with progressive deterioration in both structure and function of various molecular, cellular, and tissue components that can be influenced by both genetic and environmental factors. A number of theories have been proposed to explain the aging progress, such as shortening and/or loss of telomere, accumulation of damaged DNA in cells, and dysfunction of important cellular organelles such as the endoplasmic reticulum (ER) and mitochondria. While it is well established that aging is a major risk factor for the progression of various metabolic diseases such as central obesity, insulin resistance, hypertension and type 2 diabetes, much less is known on the links between aging and these metabolic disorders at the molecular and cellular levels.

A great progress has been made in the past decade on the association between aging and various metabolic diseases. Pharmacological or genetic manipulations of key signaling pathways involved in the regulation of glucose and energy metabolism, such as the insulin and the mammalian target of rapamycin (mTOR) signaling pathways, have been shown to improve health-span and longevity in diverse model organisms such as yeast, worms, flies, and mammals (Kennedy and Kaeberlein, 2009; McCormick et al., 2011; Laplante and Sabatini, 2012). An interesting question remains to be answered is what are the underlying mechanisms by which altering the insulin/insulin-like growth factor 1 (IGF-1) or the mTOR signaling pathway suppresses or delays aging-associated diseases and extends lifespan. There is some evidence suggesting that the maintenance of normal ER and mitochondrial function could be a primary longevity determinant. Consistent with this view, caloric restriction (CR), which is the best known intervention that prolongs lifespan in various organisms (Guarente, 2008; Kenyon, 2010), reduces mTOR and insulin/IGF-1 signaling (Bonawitz et al., 2007; Katic et al., 2007), increases mitochondrial biogenesis and/or respiratory activity (Nisoli et al., 2005; Bishop and Guarente, 2007; Zid et al., 2009), and alleviates ER stress (Tsutsumi et al., 2011). In addition to improved ER and mitochondrial function, autophagy related genes have also been found to be involved in cell survival and longevity in various long-lived mutant nematodes and promote survival in worms and flies exposed to prolonged starvation (Gomez and Clarke, 2007; Juhász et al., 2007). Current evidence shows that autophagy is required for ER stress-associated apoptosis and mitochondrial turnover, thus may mediate the integration of the insulin/IGF-1 and mTOR 


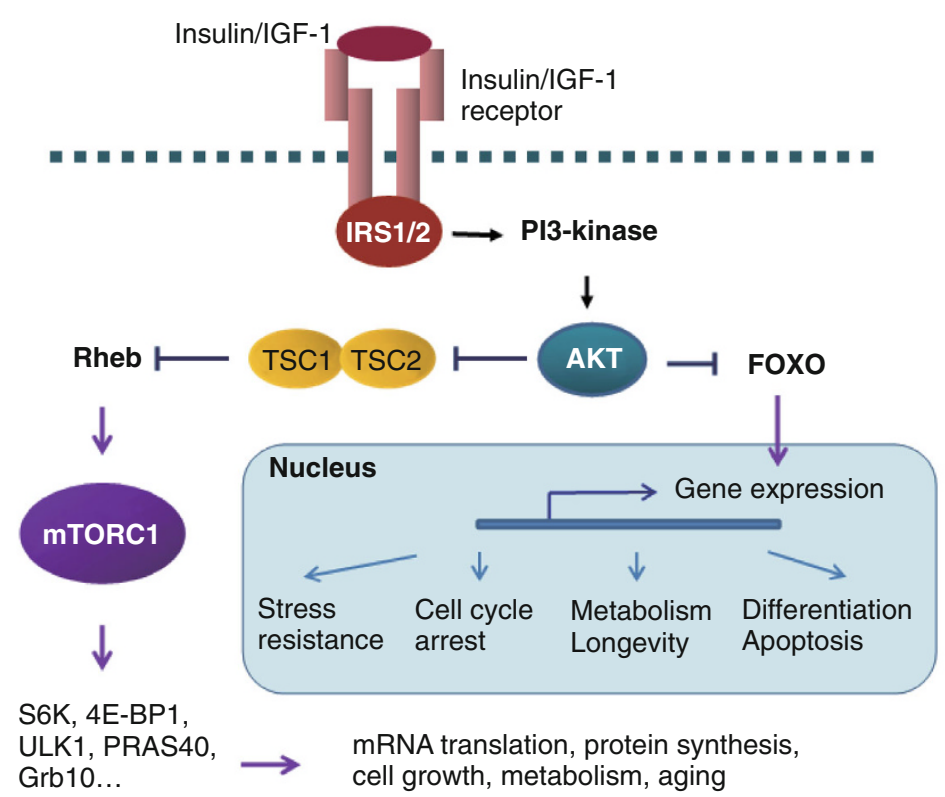

Figure 1. Insulin/IGF-1 signaling and regulation. The binding of insulin or IGF-1 to the membrane receptors leads to the activation of the PI 3-kinase/Akt signaling pathway and subsequent downstream events such as phosphorylation of FOXO1 and activation of the mTORC1 signaling pathway, which regulate many important cellular events such as mRNA translation, protein synthesis, cell cycle progression, metabolism, and aging.

signaling pathways with other cellular machineries in regulating longevity (Meijer and Codogno, 2009; Vellai, 2009). In addition, CR facilitates the degradation of damaged organelles, DNAs and protein aggregates in cells by induction of autophagy (Bergamini et al., 2003; Kim et al., 2007).

In this review, we have summarized recent progresses on the links between aging and metabolic diseases, focusing on key signaling pathways such as the insulin/IGF-1 and their tissue specific function in aging. We have also discussed several potential cellular mechanisms underlying aging and aging-associated metabolic diseases.

\section{METABOLIC SIGNALING PATHWAYS}

\section{Insulin/IGF signaling in metabolic regulation and aging}

The insulin/IGF-I signaling pathway plays an essential role in the regulation of various cellular activities such as lipid and carbohydrate metabolism, gene expression, and cell differentiation, growth, and survival. It is the first discovered and evolutionarily conserved signaling pathway involved in the determination of lifespan and is probably the best characterized regulator of longevity across species (Kenyon, 2010, 2011).

Insulin/IGF1 stimulates tyrosine phosphorylation of the insulin receptor (IR) and its substrate (IRS) proteins, IRS1 and IRS2, which, in turn, activate the phosphoinositide 3-kinase (PI3K)/AKT signaling pathway (Fig. 1). Numerous AKT substrates have been identified, including the forkhead box $\mathrm{O}$ (FOXO) protein, tuberous sclerosis 2 (TSC2), and many others. Members of the FOXO transcription factor family (FOXO1, FOXO3a, FOXO4, and FOXO6 in mammalians; DAF-16 and DFOXO in C. elegans and Drosophila, respectively) control the expression of genes involved in the regulation of cell cycle, apoptosis, DNA repair, metabolism, oxidative stress resistance, and aging. The insulin/IGF-1 signaling pathways are highly conserved across species throughout evolution, ranging from worms, flies, rodents to humans, demonstrating the importance of this signaling pathway in the maintenance of normal physiological activities and longevity in these species (van der Horst and Burgering, 2007; Narasimhan et al., 2009).

Suppressing the insulin/IGF-I signaling pathway has been shown to increase lifespan and delay aging process in species ranging from C. elegans (Wolkow et al., 2000; Wolff and Dillin, 2006), yeast (Fabrizio et al., 2001), Drosophila (Clancy et al., 2001; Tatar et al., 2001; Zhang et al., 2009) to rodents (Holzenberger et al., 2003). In C. elegans, loss-offunction mutations of the DAF-1/FOXO upstream kinases such as DAF-2 and aging alteration-1 (age-1) promoted DAF-16/FOXO protein translocation into the nucleus to activate or repress its target genes (Kenyon, 2005; Calnan and Brunet, 2008). Extended longevity is also observed in C. elegans with mutations in age-1 and daf-2, which encode the catalytic subunit of the worm PI3K and the insulin/IGF-1 receptor, respectively (Garsin et al., 2003; Murakami et al., 2005). In Drosophila, disrupting the expression levels of chico, a mammalian IRS homology, resulted in enhanced 
immune function, improved behavior, and extended lifespan (Martin and Grotewiel, 2006; Libert et al., 2008). Mice lacking IRS-1, although showed mild insulin resistance when young, not only lived longer but also maintained better glucose homoeostasis compared to wild-type controls at older ages (Selman et al., 2009). Consistent with improved metabolic functions, these mice also displayed improved immune profile and motor performance, as well as lowered incidence of osteoporosis, cataract, and ulcerative dermatitis (Selman et al., 2009). Interestingly, mice with a fat-specific insulin receptor knockout show reduced fat mass, alleviated agerelated obesity and metabolic abnormalities, and extended lifespan (Bluher et al., 2003; Katic et al., 2007), suggesting a tissue-specific role of the insulin signaling pathway in regulating health span. A correlation relationship between low plasma insulin concentration and reduced mortality risk and lower insulin resistance is also observed in humans (Richardson et al., 2004).

How reducing insulin/IGF-I levels or signaling delays aging-associated diseases and promotes healthy aging? One possible mechanism is through alterations in cell proliferation and apoptosis, which would decrease the incidence of cancer in animals (Hursting et al., 2003). Additionally, reducing insulin/IGF-1 signaling may alter the sensitivity of the animals to oxidative stress and reducing the accumulation of oxidative damage (Richardson et al., 2004; van der Horst and Burgering, 2007). Furthermore, reducing insulin/ IGF-1 levels and/or signaling may protect neurons from aging-associated degeneration in the central nervous system (Broughton and Partridge, 2009). Aberrant protein aggregation is a common feature of late-onset neurodegenerative diseases such as Alzheimer's disease and inhibition of the insulin/IGF signaling pathway has been shown to reduce the toxic aggregate prone proteins in a worm model of Alzheimer's disease (Cohen et al., 2006; Pinkston-Gosse and Kenyon, 2007). Finally, low insulin/IGF-1 signaling may have anti-aggregation effects that help to maintain cellular protein homeostasis (Morley et al., 2002; Cohen et al., 2006).

A question remains to be answered is how reducing insulin signaling, which is associated with various agingassociated metabolic and cardiovascular diseases such as obesity, type 2 diabetes, and hypertension (Rowe et al., 1983; Kohrt et al., 1993; Finkel and Holbrook, 2000), extends lifespan. Even more puzzling, insulin sensitivity has been shown to be improved by $\mathrm{CR}$ and exercise, two types of manipulation that extend longevity (Barger et al., 2003; Teramoto and Bungum, 2010). However, it is interesting to notice that knockout of the insulin receptor in fat tissues increased insulin sensitivity and extend lifespan in mice (Bluher et al., 2003; Katic et al., 2007), suggesting that tissue-specific alteration of the insulin signaling pathway could be the key to promote longevity. Another possible mechanism may be that reducing insulin/IGF-1 signaling leads to down-regulation of certain downstream aging-promoting signaling pathways. Consistent with this, reducing the mTOR signaling pathway, which is known to be activated by insulin and IGF-1 (Astrinidis and Henske, 2005; Taguchi and White, 2008) (Fig. 1), has been shown to improve healthy aging and extend lifespan (Zoncu et al., 2011).

\section{mTOR signaling: linking energy homeostasis to aging}

mTOR is a Ser/Thr protein kinase that integrates signals originating from changes in growth factors, nutrient availability, energy status, and various physiological stresses (Wullschleger et al., 2006; Liu et al., 2009). Convergence of these internal and external signals to the mTOR complex, in turn, triggers various downstream outputs such as mRNA translation, protein synthesis, autophagy, cell proliferation, growth, and survival, which are critical for the lifespan of organisms (Kennedy and Kaeberlein, 2009; McCormick et al., 2011; Zoncu et al., 2011).

mTOR functions in cells by formation of two distinct complexes, mTOR complex 1 (mTORC1) and mTOR complex 2 (mTORC2). These complexes contain unique and shared components and have distinct biological functions in response to nutrients and growth factors (Liu et al., 2009). Both mTORC1 and mTORC2 contain mTOR, mammalian lethal with SEC13 protein 8 (mLST8; also known as G $\beta L$ ), and DEP domain-containing mTOR-interacting protein (DEPTOR). However, mTORC1 contains unique accessory proteins including regulatory-associated protein of $\mathrm{mTOR}$ (RAPTOR) and $40 \mathrm{kDa}$ Pro-rich AKT substrate (PRAS40; also known as AKT1S1) whereas mTORC2 contains rapamycin-insensitive companion of mTOR (RICTOR) and other proteins, which distinguish this complex from the mTORC1 (Zoncu et al., 2011).

mTORC1 is rapamycin sensitive and plays a critical role in regulating $\mathrm{mRNA}$ translation and protein synthesis in response to nutrients, growth factors, energy, and stress (Zoncu et al., 2011). mTORC1 activity is negatively regulated by the TSC1/2 complex, which inhibits Ras homologue enriched in brain (Rheb), a small guanosine triphosphatase (GTPase) that activates mTOR, via its GTPase-activating protein (GAP) activity (Fig. 1). Growth factors such as insulin and IGF-1 promote AKT-mediated phosphorylation of TSC2, which inhibits the GAP activity of the protein and thus accumulation of Rheb-GTP complex in cells, leading to subsequent activation of mTOR. Phosphorylation of TSC2 by AKT thus provides a direct link between insulin signaling and the nutrient sensor mTOR signaling cascade (Astrinidis and Henske, 2005; Taguchi and White, 2008).

In addition to growth factors, the mTORC1 signaling pathway is also regulated by nutrients such as glucose and amino acids, involving the interaction of mTORC1 with Rag proteins, a different set of small GTPases (Sancak et al., 2008). Very recently, a protein complex named GAP activity toward Rags (GATOR) was identified as a key negative regulator of amino acid-mediated $\mathrm{mTORC} 1$ signaling (BarPeled et al., 2013; Panchaud et al., 2013). Based on the 
affinity of protein-protein interactions and their effects on mTORC1, the GATOR proteins can be divided into two subcomplexes, GATOR1 and GATOR2. Inhibition of GATOR1 leads to mTORC1 activation while inhibition of GATOR2 results in mTORC1 inactivation (Bar-Peled et al., 2013). Despite extensive studies on the functional roles of the mTORC1 signaling pathway, only a few direct substrates of mTORC1, including 4E-binding proteins (4E-BPs), $40 \mathrm{~S}$ ribosomal protein S6 kinases (S6Ks) (Martin and Blenis, 2002; Hay and Sonenberg, 2004), the autophagy inducer ULK1 (Hosokawa et al., 2009; Kim et al., 2011), and PRAS40 (Oshiro et al., 2007; Wang et al., 2008), have been found. Very recently, the growth factor receptor binding protein 10 (Grb10) has been identified as a direct substrate of mTORC1 and phosphorylation of Grb10 by mTORC1 has been suggested to enhance the feedback inhibition of the insulin/IGF-1 signaling pathways (Hsu et al., 2011; Yu et al., 2011) (Fig. 1). However, it is currently unknown whether Grb10 regulates $\mathrm{mTORC} 1$ signaling and action in vivo.

Studies during the past several years have demonstrated that the mTORC1 signaling pathway contributes to aging and metabolism. Inhibition of the MTORC1 signaling pathway extends lifespan in various model animals, ranging from yeast (Kaeberlein et al., 2005a; Bonawitz et al., 2007; Pan and Shadel, 2009), C. elegans (Vellai et al., 2003), fly (Kapahi et al., 2004), to rodents (Harrison et al., 2009; Selman et al., 2009), thus establishing a close relationship between metabolism and aging. Studies from invertebrate models first demonstrated that inhibition of the mTOR signaling pathway is sufficient to reduce protein synthesis and increase lifespan (Vellai et al., 2003; Kapahi et al., 2004; Kaeberlein and Kennedy, 2008; Stanfel et al., 2009). Consistent with these findings, pharmacological inhibition of the mTORC1 signaling pathway with rapamycin confers a robust lifespan extension in genetically heterogeneous mice (Harrison et al., 2009), yeast (Bonawitz et al., 2007), and fruit flies (Kapahi et al., 2004). Inhibition of the mTOC1 signaling pathway has also been shown to inhibit age-related weight gain, decrease aging rate, and delay spontaneous cancer in normal inbred female mice (Anisimov et al., 2011). Taken together, these results support the view that altering metabolism by inhibition of the mTORC1 signaling pathway may be an effective approach for improving health-span and extending lifespan (Kennedy and Kaeberlein, 2009). Consistent with this, mutation of daf-15, the homolog of the mTOR positive regulator RAPTOR in nematodes, led to extended lifespan (Jia et al., 2004). However, the effects of RAPTOR knockout seem to be tissue specific in mice (Polak and Hall, 2009). Adipose-specific RAPTOR knockout mice show similar properties with those long-lived mice, including increased leanness and resistance to diet-induced obesity accompanied by improved glucose tolerance and insulin sensitivity (Polak and Hall, 2009). However, knockout of RAPTOR in skeletal muscle led to muscular dystrophy associated with reduced mitochondrial biogenesis and muscle oxidative capacity but enhanced glycogen storage (Bentzinger et al., 2008). These findings suggest that reduced mTORC1 activity may be beneficial in some tissues while harmful in others. In addition to altering the expression levels of these mTOR regulators, disruption of the expression/activity of mTORC1 substrate S6K has also been shown to extend lifespan in worms (Jia et al., 2004; Hansen et al., 2007), flies (Kapahi et al., 2004), and female mice (Selman et al., 2009). However, whether tissue-specific suppression of S6K has a promoting effect on longevity in higher organisms remains to be established.

The mTORC2 may also be involved in regulation of metabolism and lifespan. On normal diet, mutations of the C. elegans homolog of RICTOR, an mTORC2 component, have been shown to increase body fat, slow development, reduce body size, and increase aging rate. However, on nutrient-rich diet, RICTOR mutants showed a profoundly extended life span, which is consistent with decreased consumption of nutrient-rich food by mutants (Soukas et al., 2009). These results indicate that RICTOR plays a critical role in appropriately partitioning calories between long-term energy stores and vital organism processes (Soukas et al., 2009).

Unlike adipose-specific RAPTOR knockout mice, which are resistant to diet-induced obesity (Polak and Hall, 2009), adipose-specific knockout of RICTOR resulted in increased body and organ sizes, independent of dietary fat content (Cybulski et al., 2009). Fat-specific knockout of RICTOR has also been shown to impair insulin-regulated whole body glucose and lipid metabolism (Kumar et al., 2010). However, the effect of fat-specific RICTOR knockout on longevity is currently unclear.

\section{MECHANISMS UNDERLYING THE BENEFICIAL EFFECTS OF SUPPRESSING INSULIN/IGF-1 AND MTOR SIGNALING ON LONGEVITY}

Although considerable data have demonstrated that suppression of the insulin/IGF-1 and mTOR signaling pathways are linked to lifespan extension, the underlying mechanisms remain elusive. During the past several years, new evidence begins to emerge on a functional link between these signaling pathways and several key cellular events such as autophagy and the function of ER and/or mitochondria, shedding light on the mechanisms by which suppressing insulin/IGF-1 and mTOR signaling pathways leads to improved longevity and healthy aging (Fig. 2).

\section{Autophagy: roles in metabolism and aging}

Autophagy is a conserved catabolic process that delivers damaged organelles or long-lived proteins to lysosomes for bulk degradation (Kroemer and Levine, 2008; Rubinsztein et al., 2011), which is considered as a mechanism that 


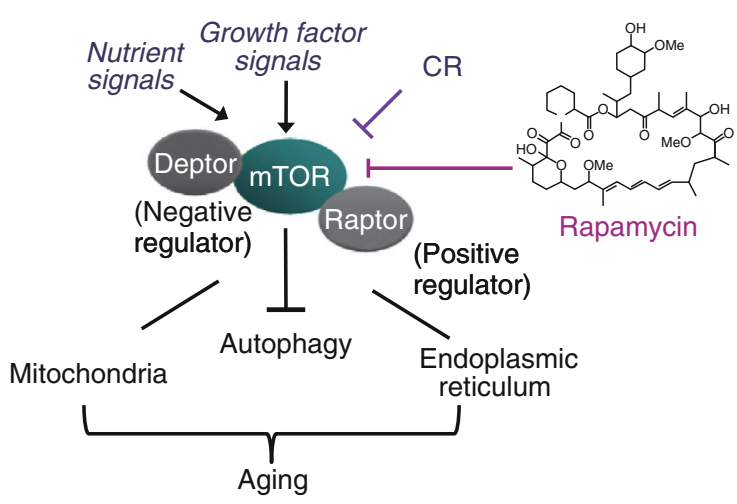

Figure 2. Manipulation of the mTORC1 signaling pathway can promote lifespan extension and healthy aging. As a central energy sensor, the mTORC1 signaling pathway is regulated by various upstream signals such as nutrients, growth factor signaling, and caloric restriction (CR), leading to altered Endoplasmic reticulum (ER) and mitochondrial function and autophagic activity, which play critical roles in aging.

protects cells against accumulation of damaged organelles and DNA, misfolded proteins, and allows cells to mobilize their energy reserves in response to nutrients depletion, hypoxia, and ER stress (Gonzalez-Polo et al., 2005; Kouroku et al., 2007; Galluzzi et al., 2008; Morselli et al., 2010). During the autophagic process, pre-autophagosome elongates and fuses to form double-membrane vesicle autophagosomes within the cytoplasm. The autophagosomes fuse with acidic lysosomes where the entrapped contents are degraded by proteases. The ER, mitochondria as well as plasma membrane are the major membrane sources contributing to the maturation of pre- or autophagosomal structures (Hayashi-Nishino et al., 2009; Hailey et al., 2010; Ravikumar et al., 2010). More than 30 different genes regulating autophagy have been identified and characterized so far. These autophagy-related genes (Atg) play important roles in the key stages of autophagy process including initiation, elongation, maturation, and fusion with the lysosomes (Ravikumar et al., 2010).

Autophagy is essential for the maintenance of cellular homeostasis and its dysregulation is involved in many metabolic disorders including obesity and insulin resistance, as well as in aging (Meijer and Codogno, 2009; Vellai, 2009; Rubinsztein et al., 2011). Defects in autophagy have been shown to reduce insulin sensitivity in the liver of obese mice with insulin resistance and hyperinsulinemia (Liu et al., 2009; Codogno and Meijer, 2010; Yang et al., 2010). On the contrary, over-expression of Atg7, an important gene for autophagy formation, diminished ER stress, improved hepatic insulin sensitivity and fat metabolism, as well as increased peripheral glucose disposal in high fat diet (HFD)fed or in ob/ob mice (Yang et al., 2010). The suppressive effect of insulin on autophagy in the liver is mediated by FoxO1-mediated transcriptional regulation of Atg genes (Liu et al., 2009). In muscle cells, FoxO3 induces expression of a number of autophagy-related genes in response to fasting and denervation (Mammucari et al., 2007; Zhao et al., 2007), and coordinately regulates the activity of both autophagy and the ubiquitin-proteasome associated degradation system in muscle cells (Ravikumar et al., 2010). However, autophagy may action differently in other tissues. In obesity, autophagy has also been found to mediate ER stress-induced reduction of IR and adiponectin in adipose tissues (Chiocchetti et al., 2007; Zhou and Liu, 2010; Zhou et al., 2010). In pancreatic beta cells, autophagy is increased during the initial period of HFD feeding presumably for protecting the beta cells as a compensatory mechanism to boost their insulin production (Ebato et al., 2008). Thus, there may be tissue-specific action of autophagy under the conditions of obesity and insulin resistance.

mTORC1 is an essential negative regulator of autophagy (Takeshige et al., 1992; Ravikumar et al., 2010; Yu et al., 2010). Several mTORC1 target genes, including Atg13, $U L K 1$, and $U L K 2$, are found to be involved in the initiation step of autophagosome formation in mammalian cells (Kim et al., 2011; Shang and Wang, 2011). Atg13 and ULK1/2 interact with FIP200 to form a ULK1/2-Atg13-FIP200 stable complex that signals to the autophagic machinery downstream of mTOR (Hay and Sonenberg, 2004; Ganley et al., 2009; Hosokawa et al., 2009). Under nutrient-rich conditions, mTORC1 suppresses autophagy through direct interaction with this complex, which leads to phosphorylation-dependent inhibition of Atg13 and ULK1 (Ravikumar et al., 2010; Shang and Wang, 2011). Under the conditions of starvation or rapamycin treatment, however, mTORC1 dissociates from the complex, leading to dephosphorylation-dependent activation of ULK1 and ULK2, which finally triggers autophagy (Ganley et al., 2009; Hosokawa et al., 2009; Kamada et al., 2010). On the other hand, however, mTOR may be feedback-regulated by autophagy. Overexpression of Atg1 inhibits TOR signaling in Drosophila, presumably as a negative feedback on the activity of TOR and to further enhance induction of autophagy (Scott et al., 2007).

Accumulating evidence suggests that autophagy-associated signaling and genes are involved in cell survival, cell death, and aging (Meijer and Codogno, 2009; Vellai, 2009). It has been observed that autophagic activity declines with age and this decline is associated with accumulation of damaged proteins and organelles, a common characteristic feature of aging (Vittorini et al., 1999; Cuervo and Dice, 2000). Upregulation of important components of the autophagy process prevents age-dependent neuronal damage and enhances longevity in Drosophila (Simonsen et al., 2008). Mutation of autophagy-related gene Atg7 results in hypersensitive to nutrient and oxidative stress and decreased lifespan in Drosophila (Juhász et al., 2007). In addition, induction of autophagy by pharmacological reagents such as rapamycin, resveratrol or the natural polyamine spermidine, caloric restriction, or genetic manipulations such as knocking down the autophagy inhibitor p53, all have been shown to 
improve animal survival and reduce age-related mortality in C. elegans (Jia et al., 2004; Tavernarakis et al., 2008). Recent studies indicate that autophagy may modulate aging in germline-less $C$. elegans through coordination with lipid metabolism to prolong life span in a mTOR-dependent manner (Lapierre et al., 2011, 2012). Furthermore, inhibition of autophagy by knocking-out or knocking-down essential Atg genes leads to apoptosis or necrosis and prevents the longevity promoting effect of CR (Meléndez et al., 2003; Boya et al., 2005; Madeo et al., 2010).

An interesting question remains to be fully addressed is whether activation of autophagy mediates the beneficial effects of suppressing insulin/IGF-1 or mTOR signaling on longevity. The studies in various invertebrate animal models demonstrate that autophagy may be involved in mTOR signaling-associated lifespan regulation. Earlier studies show that autophagy is essential for dauer development and lifespan extension in C. elegans (Meléndez et al., 2003). The mutation of worm bec-1 (Beclin 1), homologue of yeast VPS30/mammalian beclin1, as well as atg-7 and atg-12, blocks lifespan extension by a daf-2 mutant (Clancy et al., 2001; Meléndez et al., 2003). Indeed, autophagy activation has been found to be a common feature of all the long-lived mutant worms (Hansen et al., 2008; Toth et al., 2008). In yeast, autophagy is required for normal survival as well as lifespan extension by rapamycin (Alvers et al., 2009a, 2009b). Similar results were found in Drosophila, in which inhibition of autophagy abrogates rapaymcin-dependent lifespan extension (Bjedov et al., 2010). Furthermore, studies in fly and mouse models of Huntington disease discovered that inhibition of mTOR induces autophagy and reduces toxicity of polyglutamine expansions and aggregate formation (Ravikumar et al., 2004). However, whether autophagy plays similar roles in decreased metabolic signaling associated lifespan extension in vertebrates still needs to be clarified.

$\mathrm{CR}$ is the most efficient inducer of autophagy and inhibition of autophagy diminishes the anti-aging effects of $C R$ in all species investigated (Levine and Kroemer, 2008; Rubinsztein et al., 2011). CR-induced autophagy may be mediated by activation of either AMP-activated protein kinase (AMPK) or Sirtuin 1 (SIRT1) (Cantó et al., 2010; Morselli et al., 2010), two important cellular energy sensors. Moreover, CR can induce autophagy through the inhibition of insulin/IGF-1 and mTOR signaling pathways (Kenyon, 2010).

\section{ER stress: role in insulin/IGF-1 and mTOR signaling and aging}

ER plays critical roles in protein translation, folding, modification, and transportation to its final cellular destination. Under pathophysiological conditions in which increased misfolded or mutant proteins accumulated in the lumen, ER initiates an adaptive stress response pathway known as unfolded protein response (UPR) to reestablish protein equilibrium (Harding and Ron, 2002; Ron and Walter, 2007; Yoshida, 2007; Ron and Hubbard, 2008).

ER stress was first identified as a response to glucose limitation, which leads to accumulation of misfolded proteins in the ER due to impaired protein glycosylation. It was later shown that UPR could be activated in response to both glucose and oxygen deprivation thus functions as a sensor for cell energy status (Kauffman et al., 2002). Numerous studies have demonstrated that ER stress plays a critical role in the progress of chronic metabolic diseases such as obesity, insulin resistance, and type 2 diabetes (Harding and Ron, 2002; Fonseca et al., 2007; Hotamisligil, 2010), as well as atherosclerosis (Vasa-Nicotera, 2004; Zhao and Ackerman, 2006) and the aging-related neurodegenerative diseases (Lindholm et al., 2006; Yoshida, 2007). Thus, ER stress response and related signaling networks are emerging as potential intersection sites of metabolic disease and longevity.

Aging is associated with a decline in the expression and activity of several key molecular chaperones and folding enzymes responsible for proper protein folding and the adaptive response of the UPR, including immunoglobulin heavy chain-binding protein $(\mathrm{BiP}) /$ glucose regulated proteins 78 (GRP78), calnexin, calreticulin, and protein disulfide isomerase (PDI) (Naidoo, 2009), which may partly attribute to age-associated increase in protein misfolding and aggregation. However, some other ER stress related proteins such as the pro-apoptotic marker CCAAT/enhancer-binding protein-homologous protein (CHOP) and ER induced apoptosis marker caspase-12 are increased during aging. CHOP levels are elevated in the brain and other tissues of aged mice (Paz Gavilan et al., 2006; Naidoo et al., 2008) and in aged animals with sleep deprivation-induced ER stress (Naidoo et al., 2008). It is well established that CHOP mediates apoptosis in response to ER stress (Wang et al., 1996; Zinszner et al., 1998; Tabas and Ron, 2011). Elevated CHOP levels have also been shown to sensitize cells to oxidative insults (Ikeyama et al., 2003) and increase ROS levels in rat fibroblasts (McCullough et al., 2001).

Information on the link between insulin/IGF-1 or mTOR signaling and ER stress in life span determination remains limited. However, available evidence suggests a close link between these metabolic signaling pathways and ER, which makes it a potential anti-aging target. Induction of ER stress by chemicals or obesity has been suggested as a key mechanism leading to insulin resistance and type 2 diabetes (Ozcan et al., 2004, 2006). Under the condition of ER stress, activated c-Jun N-terminal kinase (JNK) inhibits insulin signaling through phosphorylation of IRS-1 at serine 307, leading to the development of insulin resistance (Aguirre et al., 2000; Hirosumi et al., 2002). Recent studies in $C$. elegans show that a decrease in the expression levels of inositol requiring enzyme 1 (IRE1) and X-box binding protein 1 (XBP-1), two key molecules involved ER-associated degradation (ERAD), shorten lifespan extension induced by 
insulin/IGF-1 signaling mutation (Henis-Korenblit et al., 2010). Notably, XBP-1 has been shown to function synergistically with DAF-16 to activate dox-1, a newly identified longevity gene, leading to enhanced resistance to ER stress and extended life span in daf-2 mutants (Henis-Korenblit et al., 2010). However, the underlying mechanisms remain elusive. It is also unclear whether the IRE-1/XBP-1 axis is altered during aging, which would impede the coordination with other stress response factors and consequently impair the ER stress response.

Emerging data indicate that ER is closely associated with the autophagic process. ER is one of the major membrane sources contributing to the maturation of pre- or autophagosomal structures and thus structurally connected to the autophagic machinery (Hayashi-Nishino et al., 2009; Hailey et al., 2010). In addition to the structural connection, ER also functions closely with autophagy under both physiological and pathophysiological conditions. It has been shown that ER stress induces autophagy in mammalian cells (Ogata et al., 2006), which provides an alternative mechanism to remove misfolded proteins that cannot be degraded by ERAD and thus assists ER homeostasis and cell survival (Ding and Yin, 2008). Phosphorylation of PKR-like eukaryotic initiation factor $2 \alpha$ kinase (PERK) and eukaryote initiation factor $2 \alpha$ (elF2), two molecules important for translational regulation and cell survival during ER stress, has been shown to be essential for autophagy formation (Kouroku et al., 2007). As a result, defected autophagy in liver leads to ER stress and insulin resistance in obesity (Codogno and Meijer, 2010; Yang et al., 2010).

Although both mTOR and ER stress signaling have attracted wide attention in fundamental cell biology and drug discovery, evidence on the crosstalk between the two pathways has emerged only very recently (Appenzeller-Herzog and Hall, 2012). As a key regulator of protein synthesis, mTORC1 controls both upstream and downstream of ER stress signals. Conversely, ER stress is able to activate mTORC1 via ATF6a, which triggers the PI3K pathway and increases the levels of RHEB by unknown mechanisms (Appenzeller-Herzog and Hall, 2012). Chronic ER stress leads to phosphorylation of the mTORC2 component RICTOR by GSK3b, resulting in suppression of Akt activation and glucose metabolism (Chen et al., 2011).

The interplay between mTOR signaling and UPR is particularly important in stress-induced apoptosis. Under unfavorable growth conditions, activation of TSC1/TSC2 would inhibit cell growth and thus protects cells from the harmful environment. While under the conditions of TSC mutation or rich in nutrients, mTORC1 is constitutively activated to stimulate translation and promotes cell growth, which has been found to cause ER stress (Ozcan et al., 2004; Kang et al., 2011). Cells with mutation in either TSC1 or TSC2 are hypersensitive to ER stress and undergo apoptosis. In addition, defects in ER stress response in TSC mutant cells could be restored by RAPTOR knockdown or by RHEB activation (Kang et al., 2011), demonstrating a functional link between mTOR signaling and ER stress. Consistent with this, a recent study found that ER stress robustly activated mTORC1, which in turn induced apoptosis (Kato et al., 2012). However, while these results demonstrate a positive relationship between ER stress and mTOR in apoptosis, other studies suggest a negative correlation between ER stress and mTOR. TSC-deficient cells have been found to be more resistant to ER stress-induced autophagy, probably due to constitutive activation of mTOR (Qin et al., 2010). In response to oxidative and ER stress, activating transcription factor 4 (ATF4) and CCAAT/enhancer-binding protein-beta (C/EBP-beta) negatively regulate mTOR by stimulating the expression of Redd1 (Jin et al., 2009), a known inhibitor of mTOR (Corradetti et al., 2005) whose expression is induced by a variety of cellular stress conditions, including hypoxia and energy stress (Sofer et al., 2005).

Although direct evidence remains limited, some indirect evidence postulates a potential linkage between ER stress and mTOR in lifespan determination. Studies in worms show that some genes that are involved in ER stress mediate lifespan extension and TOR signaling (Jia et al., 2004; Steffen et al., 2008). For example, GCN4, a nutrientresponsive transcription factor that regulates diverse cellular processes including autophagy and ER stress response (Natarajan et al., 2001; Patil et al., 2004), has been found to mediate lifespan extension in yeast (Steffen et al., 2008). In addition, the hypoxia inducible factor-1 (HIF-1), one of the targets of the mTOR pathway in mammalian cells, has been shown to be involved in CR-induced lifespan extension in $C$. elegans (Jia et al., 2004).

\section{Mitochondria: the cellular powerhouse and a primary determinant of longevity}

Mitochondrion is another important player that may mediate insulin/IGF-1 or mTOR signaling in aging. As major energygenerating organelles in eukaryotic cells, mitochondria are essential in maintaining cellular energy supplies by generating adenosine triphosphate (ATP) through oxidative phosphorylation (OXPHOS). Mitochondria are also one of the primary sites for the production of reactive oxygen species (ROS), which are generated as a toxic by-product during OXPHOS. Various studies have demonstrated that increased ROS and oxidative stress as one of the important causes of mammalian aging (Harman, 1956; Finkel and Holbrook, 2000; Wallace, 2005).

It is well established that mitochondrial function and activity are primary determinants of longevity. Defects in mitochondrial function and/or reduction in mitochondrial numbers are closely associated with many age-related diseases, including metabolic syndrome, neurodegenerative diseases, and cancer (Wallace, 2005). A progressive loss of mitochondrial energetic capacity, which is observed in diverse organisms including humans, is linked to age- 
associated decline in the expression of genes important for mitochondrial electron transport chain (ETC) function and energy metabolism (Petersen et al., 2003; McCarroll et al., 2004; Zahn et al., 2006).

Insulin/IGF-1 signaling has been shown to regulate mitochondrial DNA and OXPHOS protein syntheses, oxidative capacity, and ATP production and dysregulation in insulin signaling is associated with mitochondrial dysfunction that leads to various metabolic diseases (Kelley et al., 2002; Lowell and Shulman, 2005), although the causal relationship between insulin resistance and mitochondrial dysfunction remains to be further defined (Turner and Heilbronn, 2008). It is still puzzling as to whether and how suppressed insulin/ IGF-1 signaling is associated with improved mitochondrial function in longevity. Studies in a mouse model of Huntington's disease show that reducing IRS2 level in brain induces lifespan extension of animals with improved mitochondrial function, autophagy, and oxidative stress resistance (Sadagurski et al., 2011), which is linked to increased nuclear localization of the transcription factor FOXO1 and expression of FOXO1-dependent genes that exert these beneficial effects. However, another study found that knockout of both Irs-1 and Irs-2 in the liver activated the FOXO1 target gene Hmox1 (heme oxygenase-1), leading to disruption of complex III and IV of the respiratory chain, lower NAD ${ }^{+} / \mathrm{NADH}$ ratio, and reduced ATP production (Cheng et al., 2009). Apparently, there is a tissue-specific regulation of mitochondrial activity by insulin in aging.

The mTOR signaling has been shown as a direct regulator of mitochondrial function (Ramanathan and Schreiber, 2009). In skeletal muscle, inhibition of mTOR by rapamycin decreases the gene expression of peroxisome proliferator-

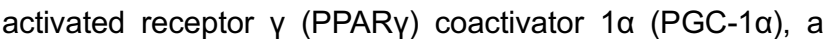
master regulator of mitochondrial biogenesis in many tissues, and estrogen-related receptor $\alpha$ and nuclear respiratory factors, resulting in a decrease in mitochondrial gene expression and oxygen consumption (Schieke et al., 2006; Narasimhan et al., 2009; Hwang et al., 2012), suggesting a positive role of mTOR in mitochondrial function.

Interestingly, a series of studies conducted in yeast showed that inhibition of TOR signaling extended life span via modulation of mitochondrial respiration, function, and gene expression. For example, deletion of the RAPTOR extended lifespan in yeast by increasing mitochondrial respiration via enhanced translation of mtDNA-encoded oxidative phosphorylation complex subunits (Bonawitz et al., 2007). Reducing TORC1 signaling by rapamycin couples respiration and ROS during growth, which extends chronological lifespan in yeast (Pan et al., 2011).

Accumulation of damaged proteins in mitochondria is a feature common to all aged cells. Mitochondria damageinduced autophagy or "mitophagy" is one of the major degradation pathways in mitochondrial turnover and homeostasis (Kim et al., 2007). Age-associated loss of autophagy leads to accumulation of damaged mitochondria, which triggers cell death and inflammation (Green et al., 2011). Mitophagy can be induced by nutrient deprivation, oxidative stress, hypoxia, mitochondrial dysfunction, and alterations of mitochondrial permeability transition (MPT) (Lemasters, 2005). Elimination of damaged mitochondria by autophagy serves as a rescue mechanism for cells to escape from cell death (Codogno and Meijer, 2005). Recent studies show that targeted mitochondrial damage led to up-regulation of autophagy genes LC3B, ATG5, and ATG12 in human endothelial cells (Mai et al., 2012). On the other hand, overexpression of these genes improved mitochondrial membrane potential and enhanced ATP production, which might contribute to increased cellular longevity (Mai et al., 2012).

Some major neurodegenerative diseases, including Parkinson's disease (PD), Huntington's disease, and Alzheimer's disease, are linked to defects in mitochondria and autophagy. PD is caused by the selective loss of dopaminergic neurons, which can be induced by mitochondrial toxins. Several genes, inlcuding PINK1 (phosphatase and tensin homolog (PTEN)-induced putative kinase 1), Parkin, or DJ1, have been shown to play important roles in mitophagy and mutations of these genes often link to autosomal recessive PD (Geisler et al., 2010; Youle and Narendra, 2011). As a critical determinant of mitophagy, Parkin is selectively recruited to mitochondria with low membrane potential, which facilitates the engulfment of mitochondria by autophagosomes (Narendra et al., 2008). Overexpression of Parkin eliminates mitochondria with deleterious mutations in cytochrome oxidase subunit I (COXI) (Suen et al., 2010), suggesting that Parkin may mediate a mitochondrial quality control pathway to maintain organelle homeostasis. There is some evidence suggesting that mTOR may be involved in Parkin relocation and mitophagy (Gilkerson et al., 2011). However, the molecular mechanisms underlying the crosstalk between mitochondrial dysfunction and autophagy remain to be further elucidated.

\section{FUTURE DIRECTIONS AND CONCLUDING REMARKS}

Recent advances have significantly increased our understanding of how aging and health-span are regulated by metabolic signals in response to cellular, nutrient, and environmental cues. An emerging view is that aging and metabolic dysfunction are closely associated and interventions that improve metabolism may also extend lifespan. Several manipulations, such as suppressing the insulin/IGF-1 and the mTOR signaling pathways, improving ER and mitochondrial function, and activating the autophagic process, have been shown to effectively slow down the aging process in various species ranging from yeast, flies to rodents. However, while these findings raise great hope to improve health-span and extend lifespan by targeting metabolic signaling pathways, many issues remain to be resolved before these interventions can be effectively applied to clinic. One 
of the major challenges is that these metabolic signaling pathways have tissue-specific function and whole-body suppressing these pathways may lead to metabolic disorders and accelerated aging. Thus, developing therapeutic drugs targeting tissue-specific signaling pathways would be of high clinic value. One of the promising targets is adipose insulin signaling pathway. Consistent with this, fat-specific disruption of this signaling pathway led to extended lifespan and improved metabolism (Bluher et al., 2003; Katic et al., 2007). Another possible target for aging is the mTORC1 signaling pathway in adipose tissues. Suppressing insulin and mTOR signaling pathways in adipose tissues may promote the biosynthesis and secretion of adipokines that are beneficial for health. Fat-specific suppression of these signaling pathways, on the other hand, may decrease biosynthesis and secretion of adipokines that are harmful to metabolism and longevity. Consistently, significantly higher levels of adiponectin, an anti-inflammatory and insulin sensitizing adipokine, have been found in centenarians (Bik et al., 2006).

Due to the complex nature of aging and metabolism, it is not yet clear whether targeting key signaling pathways involved in metabolism in specific tissues will actually improve healthy aging in humans. It is also unclear how tissue-specific signaling pathways could be effectively and specifically targeted. New strategies to suppress tissuespecific insulin and/or the mTOR signaling pathways or to mimic $C R$ response in humans should be of significant value to improve metabolism and extend health-span. Further studies are thus warranted to elucidate the tissue-specific signaling pathways involved in the regulation of metabolism and aging, which is essential for the development of effective small compounds that exert tissue-specific function on healthy lifespan.

\section{ACKNOWLEDGEMENTS}

This work was supported by grants from the National Basic Research Program (973 Program) (Nos. 2012CB524900 and 2014CB910500) and the National Natural Science Foundation of China (Grant Nos. 31071921 to F. Hu and 81130015 to F. Liu).

\section{ABBREVIATIONS}

4E-BPs, 4E-binding proteins; AMPK, AMP-activated protein kinase; ATF4, activating transcription factor 4; Atg, autophagy-related genes; ATP, adenosine triphosphate; Beclin 1, bec-1; BiP/GRP78, binding protein/glucose regulated proteins 78; C/EBP-beta, CCAAT/ enhancer-binding protein-beta; CHOP, CCAAT/enhancer-binding protein-homologous protein; COXI, cytochrome oxidase subunit I; $\mathrm{CR}$, caloric restriction; DEPTOR, DEP domain-containing mTORinteracting protein; DKO, double-knockout; eIF2, eukaryote initiation factor $2 \alpha$; ER, endoplasmic reticulum; ERAD, ER-associated degradation; ETC, electron transport chain; FOXO, forkhead box O; GAP, guanosine triphosphatase-associated protein; Grb10, growth factor receptor binding protein 10; HFD, high fat diet; HIF-
1, hypoxia inducible factor-1; Hmox1, heme oxygenase-1; IGF-1, insulin-like growth factor 1 ; IR, insulin receptor; IRE1, inositol requiring enzyme 1; IRS, insulin receptor substrate; JNK, c-Jun $\mathrm{N}$-terminal kinase; mLST8, mammalian lethal with SEC13 protein 8; MPT, mitochondrial permeability transition; mTOR, mammalian target of rapamycin; mTORC1, mTOR complex 1; mTORC2, mTOR complex 2; OXPHOS, oxidative phosphorylation; PD, Parkinson's disease; PDI, protein disulfide isomerase; PDK1, 3phosphoinositide-dependent protein kinase 1; PGC-1 $\alpha$, peroxisome proliferator-activated receptor $\mathrm{Y}$ coactivator 1a; PI3K, phosphoinositide 3-kinase; PINK1, phosphatase and tensin homolog-induced putative kinase 1; PPARY, peroxisome proliferator-activated receptor $\mathrm{Y}$; PRAS40, 40 kDa Pro-rich AKT substrate; PTEN, phosphatase and tensin homolog; RAPTOR, regulatory-associated protein of mTOR; RHEB, Ras homologue enriched in brain; RICTOR, rapamycin-insensitive companion of mTOR; ROS, reactive oxygen species; S6Ks, S6 kinases; SIRT1, Sirtuin 1; TSC2, tuberous sclerosis 2; UPR, unfolded protein response; XBP-1, X-box-binding protein-1.

\section{COMPLIANCE WITH ETHICS GUIDELINES}

Fang $\mathrm{Hu}$ and Feng Liu declare that they have no conflict of interest.

\section{OPEN ACCESS}

This article is distributed under the terms of the Creative Commons Attribution License which permits any use, distribution, and reproduction in any medium, provided the original author(s) and the source are credited.

\section{REFERENCES}

Aguirre V, Uchida T, Yenush L, Davis R, White MF (2000) The c-Jun $\mathrm{NH}(2)$-terminal kinase promotes insulin resistance during association with insulin receptor substrate-1 and phosphorylation of Ser(307). J Biol Chem 275:9047-9054

Alvers AL, Fishwick LK, Wood MS, Hu D, Chung HS, Dunn WA Jr, Aris JP (2009a) Autophagy and amino acid homeostasis are required for chronological longevity in Saccharomyces cerevisiae. Aging Cell 8:353-369

Alvers AL, Wood MS, Hu D, Kaywell AC, Dunn WA Jr, Aris JP (2009b) Autophagy is required for extension of yeast chronological life span by rapamycin. Autophagy 5:847-849

Anisimov VN, Zabezhinski MA, Popovich IG, Piskunova TS, Semenchenko AV, Tyndyk ML, Yurova MN, Rosenfeld SV, Blagosklonny MV (2011) Rapamycin increases lifespan and inhibits spontaneous tumorigenesis in inbred female mice. Cell Cycle 10:4230-4236

Appenzeller-Herzog C, Hall MN (2012) Bidirectional crosstalk between endoplasmic reticulum stress and mTOR signaling. Trends Cell Biol 22:274-282

Astrinidis A, Henske EP (2005) Tuberous sclerosis complex: linking growth and energy signaling pathways with human disease. Oncogene 24:7475-7481

Barger JL, Walford RL, Weindruch R (2003) The retardation of aging by caloric restriction: its significance in the transgenic era. Exp Gerontol 38:1343-1351 
Bar-Peled L, Chantranupong L, Cherniack AD, Chen WW, Ottina KA, Grabiner BC, Spear ED, Carter SL, Meyerson M, Sabatini DM (2013) A tumor suppressor complex with GAP activity for the Rag GTPases that signal amino acid sufficiency to mTORC1. Science 340:1100-1106

Bentzinger CF, Romanino K, Cloetta D, Lin S, Mascarenhas JB, Oliveri F, Xia J, Casanova E, Costa CF, Brink M et al (2008) Skeletal muscle-specific ablation of raptor, but not of rictor, causes metabolic changes and results in muscle dystrophy. Cell Metab 8:411-424

Bergamini E, Cavallini G, Donati A, Gori Z (2003) The antiageing effects of caloric restriction may involve stimulation of macroautophagy and lysosomal degradation, and can be intensified pharmacologically. Biomed Pharmacother 57: 203-208

Bik W, Baranowska-Bik A, Wolinska-Witort E, Martynska L, Chmielowska M, Szybinska A, Broczek K, Baranowska B (2006) The relationship between adiponectin levels and metabolic status in centenarian, early elderly, young and obese women. Neuro Endocrinol Lett 27:493-500

Bishop NA, Guarente L (2007) Two neurons mediate diet-restrictioninduced longevity in C. elegans. Nature 447:545-549

Bjedov I, Toivonen JM, Kerr F, Slack C, Jacobson J, Foley A, Partridge L (2010) Mechanisms of life span extension by rapamycin in the fruit fly Drosophila melanogaster. Cell Metab 11:35-46

Bluher M, Kahn BB, Kahn CR (2003) Extended longevity in mice lacking the insulin receptor in adipose tissue. Science 299:572574

Bonawitz ND, Chatenay-Lapointe M, Pan Y, Shadel GS (2007) Reduced TOR signaling extends chronological life span via increased respiration and upregulation of mitochondrial gene expression. Cell Metab 5:265-277

Boya P, Gonzalez-Polo RA, Casares N, Perfettini JL, Dessen P, Larochette N, Metivier D, Meley D, Souquere S, Yoshimori Tet al (2005) Inhibition of macroautophagy triggers apoptosis. Mol Cell Biol 25:1025-1040

Broughton S, Partridge L (2009) Insulin/IGF-like signalling, the central nervous system and aging. Biochem J 418:1-12

Calnan DR, Brunet A (2008) The FoxO code. Oncogene 27:22762288

Cantó C, Jiang LQ, Deshmukh AS, Mataki C, Coste A, Lagouge M, Zierath JR, Auwerx J (2010) Interdependence of AMPK and SIRT1 for metabolic adaptation to fasting and exercise in skeletal muscle. Cell Metab 11:213-219

Chen $\mathrm{CH}$, Shaikenov T, Peterson TR, Aimbetov R, Bissenbaev AK, Lee SW, Wu J, Lin HK, Sarbassov dos D (2011) ER stress inhibits mTORC2 and Akt signaling through GSK-3beta-mediated phosphorylation of rictor. Sci Signal 4:ra10

Cheng Z, Guo S, Copps K, Dong X, Kollipara R, Rodgers JT, Depinho RA, Puigserver P, White MF (2009) Foxo1 integrates insulin signaling with mitochondrial function in the liver. Nat Med 15:1307-1311

Chiocchetti A, Zhou J, Zhu H, Karl T, Haubenreisser O, Rinnerthaler M, Heeren G, Oender K, Bauer J, Hintner $H$ et al (2007) Ribosomal proteins Rpl10 and Rps6 are potent regulators of yeast replicative life span. Exp Gerontol 42:275-286
Clancy DJ, Gems D, Harshman LG, Oldham S, Stocker H, Hafen E, Leevers SJ, Partridge L (2001) Extension of life-span by loss of $\mathrm{CHICO}$, a Drosophila insulin receptor substrate protein. Science 292:104-106

Codogno P, Meijer AJ (2005) Autophagy and signaling: their role in cell survival and cell death. Cell Death Differ 12(Suppl 2):1509-1518

Codogno P, Meijer AJ (2010) Autophagy: a potential link between obesity and insulin resistance. Cell Metab 11:449-451

Cohen E, Bieschke J, Perciavalle RM, Kelly JW, Dillin A (2006) Opposing activities protect against age-onset proteotoxicity. Science 313:1604-1610

Corradetti MN, Inoki K, Guan KL (2005) The stress-induced proteins RTP801 and RTP801L are negative regulators of the mammalian target of rapamycin pathway. J Biol Chem 280:9769-9772

Cuervo AM, Dice JF (2000) Age-related decline in chaperonemediated autophagy. J Biol Chem 275:31505-31513

Cybulski N, Polak P, Auwerx J, Ruegg MA, Hall MN (2009) mTOR complex 2 in adipose tissue negatively controls whole-body growth. Proc Natl Acad Sci USA 106:9902-9907

Ding WX, Yin XM (2008) Sorting, recognition and activation of the misfolded protein degradation pathways through macroautophagy and the proteasome. Autophagy 4:141-150

Ebato C, Uchida T, Arakawa M, Komatsu M, Ueno T, Komiya K, Azuma K, Hirose T, Tanaka K, Kominami E et al (2008) Autophagy is important in islet homeostasis and compensatory increase of beta cell mass in response to high-fat diet. Cell Metab 8:325-332

Fabrizio P, Pozza F, Pletcher SD, Gendron CM, Longo VD (2001) Regulation of longevity and stress resistance by Sch9 in yeast. Science 292:288-290

Finkel T, Holbrook NJ (2000) Oxidants, oxidative stress and the biology of ageing. Nature 408:239-247

Fonseca SG, Lipson KL, Urano F (2007) Endoplasmic reticulum stress signaling in pancreatic beta-cells. Antioxid Redox Signal 9:2335-2344

Galluzzi L, Vicencio JM, Kepp O, Tasdemir E, Maiuri MC, Kroemer G (2008) To die or not to die: that is the autophagic question. Curr Mol Med 8:78-91

Ganley IG, du Lam H, Wang J, Ding X, Chen S, Jiang X (2009) ULK1.ATG13.FIP200 complex mediates mTOR signaling and is essential for autophagy. J Biol Chem 284:12297-12305

García-Fernández M, Sierra I, Puche JE, Guerra L, Castilla-Cortazar I (2007) Liver mitochondrial dysfunction is reverted by insulin-like growth factor II (IGF-II) in aging rats. J Transl Med 9:123

Garsin DA, Villanueva JM, Begun J, Kim DH, Sifri CD, Calderwood SB, Ruvkun G, Ausubel FM (2003) Long-lived C. elegans daf-2 mutants are resistant to bacterial pathogens. Science 300:1921

Geisler S, Holmstrom KM, Skujat D, Fiesel FC, Rothfuss OC, Kahle PJ, Springer W (2010) PINK1/Parkin-mediated mitophagy is dependent on VDAC1 and p62/SQSTM1. Nat Cell Biol 12:119-131

Gilkerson RW, De Vries RL, Lebot P, Wikstrom JD, Torgyekes E, Shirihai OS, Przedborski S, Schon EA (2011) Mitochondrial autophagy in cells with mtDNA mutations results from synergistic loss of transmembrane potential and mTORC1 inhibition. Hum Mol Genet 21:978-990

Gomez TA, Clarke SG (2007) Autophagy and insulin/TOR signaling in Caenorhabditis elegans pcm-1 protein repair mutants. Autophagy 3:357-359 
Gonzalez-Polo RA, Boya P, Pauleau AL, Jalil A, Larochette N, Souquere S, Eskelinen EL, Pierron G, Saftig P, Kroemer G (2005) The apoptosis/autophagy paradox: autophagic vacuolization before apoptotic death. J Cell Sci 118:3091-3102

Green DR, Galluzzi L, Kroemer G (2011) Mitochondria and the autophagy-inflammation-cell death axis in organismal aging. Science 333:1109-1112

Guarente L (2008) Mitochondria-a nexus for aging, calorie restriction, and sirtuins? Cell 132:171-176

Hailey DW, Rambold AS, Satpute-Krishnan P, Mitra K, Sougrat R, Kim PK, Lippincott-Schwartz J (2010) Mitochondria supply membranes for autophagosome biogenesis during starvation. Cell 141:656-667

Hansen M, Taubert S, Crawford D, Libina N, Lee SJ, Kenyon C (2007) Lifespan extension by conditions that inhibit translation in Caenorhabditis elegans. Aging Cell 6:95-110

Hansen M, Chandra A, Mitic LL, Onken B, Driscoll M, Kenyon C (2008) A role for autophagy in the extension of lifespan by dietary restriction in C. elegans. PLoS Genet 4:e24

Harding HP, Ron D (2002) Endoplasmic reticulum stress and the development of diabetes: a review. Diabetes 51(Suppl 3):S455S461

Harman D (1956) Aging: a theory based on free radical and radiation chemistry. J Gerontol 11:298-300

Harrison DE, Strong R, Sharp ZD, Nelson JF, Astle CM, Flurkey K, Nadon NL, Wilkinson JE, Frenkel K, Carter CS et al (2009) Rapamycin fed late in life extends lifespan in genetically heterogeneous mice. Nature 460:392-395

Hay N, Sonenberg N (2004) Upstream and downstream of mTOR. Genes Dev 18:1926-1945

Hayashi-Nishino M, Fujita N, Noda T, Yamaguchi A, Yoshimori T, Yamamoto A (2009) A subdomain of the endoplasmic reticulum forms a cradle for autophagosome formation. Nat Cell Biol 11:1433-1437

Henis-Korenblit S, Zhang P, Hansen M, McCormick M, Lee SJ, Cary M, Kenyon C (2010) Insulin/IGF-1 signaling mutants reprogram ER stress response regulators to promote longevity. Proc Natl Acad Sci USA 107:9730-9735

Hirosumi J, Tuncman G, Chang L, Gorgun CZ, Uysal KT, Maeda K, Karin M, Hotamisligil GS (2002) A central role for JNK in obesity and insulin resistance. Nature 420:333-336

Holzenberger M, Dupont J, Ducos B, Leneuve P, Geloen A, Even PC, Cervera P, Le Bouc Y (2003) IGF-1 receptor regulates lifespan and resistance to oxidative stress in mice. Nature 421:182-187

Hosokawa N, Hara T, Kaizuka T, Kishi C, Takamura A, Miura Y, lemura S, Natsume T, Takehana K, Yamada N et al (2009) Nutrient-dependent mTORC1 association with the ULK1-Atg13FIP200 complex required for autophagy. Mol Biol Cell 20:19811991

Hotamisligil GS (2010) Endoplasmic reticulum stress and atherosclerosis. Nat Med 16:396-399

Hsu PP, Kang SA, Rameseder J, Zhang Y, Ottina KA, Lim D, Peterson TR, Choi Y, Gray NS, Yaffe MB et al (2011) The mTORregulated phosphoproteome reveals a mechanism of mTORC1mediated inhibition of growth factor signaling. Science 332: $1317-1322$
Hursting SD, Lavigne JA, Berrigan D, Perkins SN, Barrett JC (2003) Calorie restriction, aging, and cancer prevention: mechanisms of action and applicability to humans. Annu Rev Med 54:131-152

Hwang AB, Jeong DE, Lee SJ (2012) Mitochondria and organismal longevity. Curr Genomics 13:519-532

Ikeyama S, Wang XT, Li J, Podlutsky A, Martindale JL, Kokkonen G, van Huizen R, Gorospe M, Holbrook NJ (2003) Expression of the proapoptotic gene gadd153/chop is elevated in liver with aging and sensitizes cells to oxidant injury. J Biol Chem 278:16726-16731

Jia K, Chen D, Riddle DL (2004) The TOR pathway interacts with the insulin signaling pathway to regulate $C$. elegans larval development, metabolism and life span. Development 131:38973906

Jin HO, Seo SK, Woo SH, Kim ES, Lee HC, Yoo DH, An S, Choe TB, Lee SJ, Hong SI et al (2009) Activating transcription factor 4 and CCAAT/enhancer-binding protein-beta negatively regulate the mammalian target of rapamycin via Redd1 expression in response to oxidative and endoplasmic reticulum stress. Free Radic Biol Med 46:1158-1167

Juhász G, Erdi B, Sass M, Neufeld TP (2007) Atg7-dependent autophagy promotes neuronal health, stress tolerance, and longevity but is dispensable for metamorphosis in Drosophila. Genes Dev 21:3061-3066

Kaeberlein M, Kennedy BK (2008) Protein translation, 2008. Aging Cell 7:777-782

Kaeberlein M, Hu D, Kerr EO, Tsuchiya M, Westman EA, Dang N, Fields S, Kennedy BK (2005a) Increased life span due to calorie restriction in respiratory-deficient yeast. PLoS Genet 1:e69

Kaeberlein M, Powers RW 3rd, Steffen KK, Westman EA, Hu D, Dang N, Kerr EO, Kirkland KT, Fields S, Kennedy BK (2005b) Regulation of yeast replicative life span by TOR and Sch9 in response to nutrients. Science 310:1193-1196

Kamada Y, Yoshino K, Kondo C, Kawamata T, Oshiro N, Yonezawa K, Ohsumi Y (2010) Tor directly controls the Atg1 kinase complex to regulate autophagy. Mol Cell Biol 30:1049-1058

Kang YJ, Lu MK, Guan KL (2011) The TSC1 and TSC2 tumor suppressors are required for proper ER stress response and protect cells from ER stress-induced apoptosis. Cell Death Differ 18:133-144

Kapahi P, Zid BM, Harper T, Koslover D, Sapin V, Benzer S (2004) Regulation of lifespan in Drosophila by modulation of genes in the TOR signaling pathway. Curr Biol 14:885-890

Katic M, Kennedy AR, Leykin I, Norris A, McGettrick A, Gesta S, Russell SJ, Bluher M, Maratos-Flier E, Kahn CR (2007) Mitochondrial gene expression and increased oxidative metabolism: role in increased lifespan of fat-specific insulin receptor knock-out mice. Aging Cell 6:827-839

Kato H, Nakajima S, Saito Y, Takahashi S, Katoh R, Kitamura M (2012) mTORC1 serves ER stress-triggered apoptosis via selective activation of the IRE1-JNK pathway. Cell Death Differ 19:310-320

Kauffman AL, Ashraf JM, Corces-Zimmerman MR, Landis JN, Murphy CT (2002) Insulin signaling and dietary restriction differentially influence the decline of learning and memory with age. PLoS Biol 8:e1000372

Kelley DE, He J, Menshikova EV, Ritov VB (2002) Dysfunction of mitochondria in human skeletal muscle in type 2 diabetes. Diabetes 51:2944-2950 
Kennedy BK, Kaeberlein M (2009) Hot topics in aging research: protein translation, 2009. Aging Cell 8:617-623

Kenyon C (2005) The plasticity of aging: insights from long-lived mutants. Cell 120:449-460

Kenyon CJ (2010) The genetics of ageing. Nature 464:504-512

Kenyon C (2011) The first long-lived mutants: discovery of the insulin/IGF-1 pathway for ageing. Philos Trans R Soc Lond B Biol Sci 366:9-16

Kim I, Rodriguez-Enriquez S, Lemasters JJ (2007) Selective degradation of mitochondria by mitophagy. Arch Biochem Biophys 462:245-253

Kim J, Kundu M, Viollet B, Guan KL (2011) AMPK and mTOR regulate autophagy through direct phosphorylation of Ulk1. Nat Cell Biol 13:132-141

Kohrt WM, Kirwan JP, Staten MA, Bourey RE, King DS, Holloszy JO (1993) Insulin resistance in aging is related to abdominal obesity Diabetes 42:273-281

Kouroku Y, Fujita E, Tanida I, Ueno T, Isoai A, Kumagai H, Ogawa S, Kaufman RJ, Kominami E, Momoi T (2007) ER stress (PERK/ elF2alpha phosphorylation) mediates the polyglutamine-induced LC3 conversion, an essential step for autophagy formation. Cell Death Differ 14:230-239

Kroemer G, Levine B (2008) Autophagic cell death: the story of a misnomer. Nat Rev Mol Cell Biol 9:1004-1010

Kumar A, Lawrence JC Jr, Jung DY, Ko HJ, Keller SR, Kim JK, Magnuson MA, Harris TE (2010) Fat cell-specific ablation of rictor in mice impairs insulin-regulated fat cell and whole-body glucose and lipid metabolism. Diabetes 59:1397-1406

Lapierre LR, Gelino S, Melendez A, Hansen M (2011) Autophagy and lipid metabolism coordinately modulate life span in germlineless C. elegans. Curr Biol 21:1507-1514

Lapierre LR, Melendez A, Hansen M (2012) Autophagy links lipid metabolism to longevity in C. elegans. Autophagy 8:144-146

Laplante M, Sabatini DM (2012) mTOR signaling in growth control and disease. Cell 149:274-293

Lee J, Giordano S, Zhang J (2012) Autophagy, mitochondria and oxidative stress: cross-talk and redox signalling. Biochem $\mathrm{J}$ 441:523-540

Lemasters JJ (2005) Selective mitochondrial autophagy, or mitophagy, as a targeted defense against oxidative stress, mitochondrial dysfunction, and aging. Rejuvenation Res 8:3-5

Levine B, Kroemer G (2008) Autophagy in the pathogenesis of disease. Cell 132:27-42

Libert S, Chao Y, Zwiener J, Pletcher SD (2008) Realized immune response is enhanced in long-lived puc and chico mutants but is unaffected by dietary restriction. Mol Immunol 45:810-817

Lindholm D, Wootz H, Korhonen L (2006) ER stress and neurodegenerative diseases. Cell Death Differ 13:385-392

Liu HY, Yehuda-Shnaidman E, Hong T, Han J, Pi J, Liu Z, Cao W (2009) Prolonged exposure to insulin suppresses mitochondrial production in primary hepatocytes. J Biol Chem 284:14087-14095

Lowell BB, Shulman GI (2005) Mitochondrial dysfunction and type 2 diabetes. Science 307:384-387

Madeo F, Tavernarakis N, Kroemer G (2010) Can autophagy promote longevity? Nat Cell Biol 12:842-846

Maechler P, Wollheim CB (2001) Mitochondrial function in normal and diabetic beta-cells. Nature 414:807-812
Mai S, Muster B, Bereiter-Hahn J, Jendrach M (2012) Autophagy proteins LC3B, ATG5 and ATG12 participate in quality control after mitochondrial damage and influence lifespan. Autophagy 8:47-62

Mammucari C, Milan G, Romanello V, Masiero E, Rudolf R, Del Piccolo P, Burden SJ, Di Lisi R, Sandri C, Zhao J et al (2007) FoxO3 controls autophagy in skeletal muscle in vivo. Cell Metab 6:458-471

Martin KA, Blenis J (2002) Coordinate regulation of translation by the PI 3-kinase and mTOR pathways. Adv Cancer Res 86:1-39

Martin I, Grotewiel MS (2006) Distinct genetic influences on locomotor senescence in Drosophila revealed by a series of metrical analyses. Exp Gerontol 41:877-881

McCarroll SA, Murphy CT, Zou S, Pletcher SD, Chin CS, Jan YN, Kenyon C, Bargmann Cl, Li H (2004) Comparing genomic expression patterns across species identifies shared transcriptional profile in aging. Nat Genet 36:197-204

McCormick MA, Tsai SY, Kennedy BK (2011) TOR and ageing: a complex pathway for a complex process. Philos Trans $\mathrm{R}$ Soc Lond B Biol Sci 366:17-27

McCullough ME, Kilpatrick SD, Emmons RA, Larson DB (2001) Is gratitude a moral affect? Psychol Bull 127:249-266

Meijer AJ, Codogno P (2009) Autophagy: regulation and role in disease. Crit Rev Clin Lab Sci 46:210-240

Meléndez A, Talloczy Z, Seaman M, Eskelinen EL, Hall DH, Levine B (2003) Autophagy genes are essential for dauer development and life-span extension in C. elegans. Science 301:1387-1391

Mohlig M, Wegewitz U, Osterhoff M, Isken F, Ristow M, Pfeiffer AF, Spranger J (2002) Insulin decreases human adiponectin plasma levels. Horm Metab Res 34:655-658

Morley JF, Brignull HR, Weyers JJ, Morimoto RI (2002) The threshold for polyglutamine-expansion protein aggregation and cellular toxicity is dynamic and influenced by aging in Caenorhabditis elegans. Proc Natl Acad Sci USA 99:10417-10422

Morselli E, Maiuri MC, Markaki M, Megalou E, Pasparaki A, Palikaras K, Criollo A, Galluzzi L, Malik SA, Vitale I et al (2010) Caloric restriction and resveratrol promote longevity through the Sirtuin-1-dependent induction of autophagy. Cell Death Dis 1: e10

Murakami H, Bessinger K, Hellmann J, Murakami S (2005) Agingdependent and -independent modulation of associative learning behavior by insulin/insulin-like growth factor-1 signal in Caenorhabditis elegans. J Neurosci 25:10894-10904

Naidoo N (2009) ER and aging-protein folding and the ER stress response. Ageing Res Rev 8:150-159

Naidoo N, Ferber M, Master M, Zhu Y, Pack Al (2008) Aging impairs the unfolded protein response to sleep deprivation and leads to proapoptotic signaling. J Neurosci 28:6539-6548

Narasimhan SD, Yen K, Tissenbaum HA (2009) Converging pathways in lifespan regulation. Curr Biol 19:R657-R666

Narendra D, Tanaka A, Suen DF, Youle RJ (2008) Parkin is recruited selectively to impaired mitochondria and promotes their autophagy. J Cell Biol 183:795-803

Natarajan K, Meyer MR, Jackson BM, Slade D, Roberts C, Hinnebusch AG, Marton MJ (2001) Transcriptional profiling shows that Gcn4p is a master regulator of gene expression during amino acid starvation in yeast. Mol Cell Biol 21:4347-4368 
Nisoli E, Tonello C, Cardile A, Cozzi V, Bracale R, Tedesco L, Falcone S, Valerio A, Cantoni O, Clementi E et al (2005) Calorie restriction promotes mitochondrial biogenesis by inducing the expression of eNOS. Science 310:314-317

Ogata M, Hino S, Saito A, Morikawa K, Kondo S, Kanemoto S, Murakami T, Taniguchi M, Tanii I, Yoshinaga K et al (2006) Autophagy is activated for cell survival after endoplasmic reticulum stress. Mol Cell Biol 26:9220-9231

Oshiro N, Takahashi R, Yoshino K, Tanimura K, Nakashima A, Eguchi S, Miyamoto T, Hara K, Takehana K, Avruch J et al (2007) The proline-rich Akt substrate of $40 \mathrm{kDa}$ (PRAS40) is a physiological substrate of mammalian target of rapamycin complex 1. J Biol Chem 282:20329-20339

Ozcan U, Cao Q, Yilmaz E, Lee AH, Iwakoshi NN, Ozdelen E, Tuncman G, Gorgun C, Glimcher LH, Hotamisligil GS (2004) Endoplasmic reticulum stress links obesity, insulin action, and type 2 diabetes. Science 306:457-461

Ozcan U, Yilmaz E, Ozcan L, Furuhashi M, Vaillancourt E, Smith RO, Gorgun CZ, Hotamisligil GS (2006) Chemical chaperones reduce ER stress and restore glucose homeostasis in a mouse model of type 2 diabetes. Science 313:1137-1140

Ozcan U, Ozcan L, Yilmaz E, Duvel K, Sahin M, Manning BD, Hotamisligil GS (2008) Loss of the tuberous sclerosis complex tumor suppressors triggers the unfolded protein response to regulate insulin signaling and apoptosis. Mol Cell 29:541-551

Pan Y, Shadel GS (2009) Extension of chronological life span by reduced TOR signaling requires down-regulation of Sch9p and involves increased mitochondrial OXPHOS complex density. Aging (Albany NY) 1:131-145

Pan Y, Schroeder EA, Ocampo A, Barrientos A, Shadel GS (2011) Regulation of yeast chronological life span by TORC1 via adaptive mitochondrial ROS signaling. Cell Metab 13:668-678

Panchaud N, Peli-Gulli MP, De Virgilio C (2013) Amino acid deprivation inhibits TORC1 through a GTPase-activating protein complex for the Rag family GTPase Gtr1. Sci Signal 6:ra42

Patil CK, Li H, Walter P (2004) Gcn4p and novel upstream activating sequences regulate targets of the unfolded protein response. PLoS Biol 2:E246

Paz Gavilan M, Vela J, Castano A, Ramos B, del Rio JC, Vitorica J, Ruano D (2006) Cellular environment facilitates protein accumulation in aged rat hippocampus. Neurobiol Aging 27:973-982

Petersen KF, Befroy D, Dufour S, Dziura J, Ariyan C, Rothman DL, DiPietro L, Cline GW, Shulman GI (2003) Mitochondrial dysfunction in the elderly: possible role in insulin resistance. Science 300:1140-1142

Pinkston-Gosse J, Kenyon C (2007) DAF-16/FOXO targets genes that regulate tumor growth in Caenorhabditis elegans. Nat Genet 39:1403-1409

Polak P, Hall MN (2009) mTOR and the control of whole body metabolism. Curr Opin Cell Biol 21:209-218

Qin L, Wang Z, Tao L, Wang Y (2010) ER stress negatively regulates AKT/TSC/mTOR pathway to enhance autophagy. Autophagy 6:239-247

Ramanathan A, Schreiber SL (2009) Direct control of mitochondrial function by mTOR. Proc Natl Acad Sci USA 106:22229-22232

Ravikumar B, Vacher C, Berger Z, Davies JE, Luo S, Oroz LG, Scaravilli F, Easton DF, Duden R, O'Kane CJ et al (2004)
Inhibition of mTOR induces autophagy and reduces toxicity of polyglutamine expansions in fly and mouse models of Huntington disease. Nat Genet 36:585-595

Ravikumar B, Sarkar S, Davies JE, Futter M, Garcia-Arencibia M, Green-Thompson ZW, Jimenez-Sanchez M, Korolchuk VI, Lichtenberg M, Luo S et al (2010) Regulation of mammalian autophagy in physiology and pathophysiology. Physiol Rev 90:1383-1435

Richardson A, Liu F, Adamo ML, Van Remmen H, Nelson JF (2004) The role of insulin and insulin-like growth factor-I in mammalian ageing. Best Pract Res Clin Endocrinol Metab 18:393-406

Ron D, Hubbard SR (2008) How IRE1 reacts to ER stress. Cell 132:24-26

Ron D, Walter P (2007) Signal integration in the endoplasmic reticulum unfolded protein response. Nat Rev Mol Cell Biol 8:519-529

Rowe JW, Minaker KL, Pallotta JA, Flier JS (1983) Characterization of the insulin resistance of aging. J Clin Invest 71:1581-1587

Rubinsztein DC, Marino G, Kroemer G (2011) Autophagy and aging. Cell 146:682-695

Sadagurski M, Cheng Z, Rozzo A, Palazzolo I, Kelley GR, Dong X, Krainc D, White MF (2011) IRS2 increases mitochondrial dysfunction and oxidative stress in a mouse model of Huntington disease. J Clin Invest 121:4070-4081

Sancak Y, Peterson TR, Shaul YD, Lindquist RA, Thoreen CC, BarPeled L, Sabatini DM (2008) The Rag GTPases bind raptor and mediate amino acid signaling to mTORC1. Science 320:14961501

Schieke SM, Phillips D, McCoy JP Jr, Aponte AM, Shen RF, Balaban RS, Finkel T (2006) The mammalian target of rapamycin (mTOR) pathway regulates mitochondrial oxygen consumption and oxidative capacity. J Biol Chem 281:27643-27652

Scott RC, Juhasz G, Neufeld TP (2007) Direct induction of autophagy by Atg1 inhibits cell growth and induces apoptotic cell death. Curr Biol 17:1-11

Selman C, Tullet JM, Wieser D, Irvine E, Lingard SJ, Choudhury AI, Claret M, Al-Qassab H, Carmignac D, Ramadani F et al (2009) Ribosomal protein $\mathrm{S} 6$ kinase 1 signaling regulates mammalian life span. Science 326:140-144

Shang L, Wang X (2011) AMPK and mTOR coordinate the regulation of Ulk1 and mammalian autophagy initiation. Autophagy 7:924926

Simonsen A, Cumming RC, Brech A, Isakson P, Schubert DR, Finley KD (2008) Promoting basal levels of autophagy in the nervous system enhances longevity and oxidant resistance in adult Drosophila. Autophagy 4:176-184

Sofer A, Lei K, Johannessen CM, Ellisen LW (2005) Regulation of mTOR and cell growth in response to energy stress by REDD1. Mol Cell Biol 25:5834-5845

Soukas AA, Kane EA, Carr CE, Melo JA, Ruvkun G (2009) Rictor/ TORC2 regulates fat metabolism, feeding, growth, and life span in Caenorhabditis elegans. Genes Dev 23:496-511

Stanfel MN, Shamieh LS, Kaeberlein M, Kennedy BK (2009) The TOR pathway comes of age. Biochim Biophys Acta 1790:1067-1074

Steffen KK, MacKay VL, Kerr EO, Tsuchiya M, Hu D, Fox LA, Dang $\mathrm{N}$, Johnston ED, Oakes JA, Tchao BN et al (2008) Yeast life span extension by depletion of 60 s ribosomal subunits is mediated by Gcn4. Cell 133:292-302 
Suen DF, Narendra DP, Tanaka A, Manfredi G, Youle RJ (2010) Parkin overexpression selects against a deleterious mtDNA mutation in heteroplasmic cybrid cells. Proc Natl Acad Sci USA 107:11835-11840

Sunayama J, Tsuruta F, Masuyama N, Gotoh Y (2005) JNK antagonizes Akt-mediated survival signals by phosphorylating 14-3-3. J Cell Biol 170:295-304

Tabas I, Ron D (2011) Integrating the mechanisms of apoptosis induced by endoplasmic reticulum stress. Nat Cell Biol 13:184190

Taguchi A, White MF (2008) Insulin-like signaling, nutrient homeostasis, and life span. Annu Rev Physiol 70:191-212

Takeshige K, Baba M, Tsuboi S, Noda T, Ohsumi Y (1992) Autophagy in yeast demonstrated with proteinase-deficient mutants and conditions for its induction. J Cell Biol 119:301-311

Tatar M, Kopelman A, Epstein D, Tu MP, Yin CM, Garofalo RS (2001) A mutant Drosophila insulin receptor homolog that extends life-span and impairs neuroendocrine function. Science 292:107-110

Tavernarakis N, Pasparaki A, Tasdemir E, Maiuri MC, Kroemer G (2008) The effects of p53 on whole organism longevity are mediated by autophagy. Autophagy 4:870-873

Teramoto M, Bungum TJ (2010) Mortality and longevity of elite athletes. J Sci Med Sport 13:410-416

Toth ML, Sigmond T, Borsos E, Barna J, Erdelyi P, Takacs-Vellai K Orosz L, Kovacs AL, Csikos G, Sass M et al (2008) Longevity pathways converge on autophagy genes to regulate life span in Caenorhabditis elegans. Autophagy 4:330-338

Tsuchida A, Yamauchi T, Ito Y, Hada Y, Maki T, Takekawa S, Kamon J, Kobayashi M, Suzuki R, Hara K et al (2004) Insulin/Foxo1 pathway regulates expression levels of adiponectin receptors and adiponectin sensitivity. J Biol Chem 279:30817-30822

Tsutsumi A, Motoshima H, Kondo T, Kawasaki S, Matsumura T, Hanatani S, Igata $\mathrm{M}$, Ishii $\mathrm{N}$, Kinoshita $\mathrm{H}$, Kawashima $\mathrm{J}$ et al (2011) Caloric restriction decreases ER stress in liver and adipose tissue in ob/ob mice. Biochem Biophys Res Commun 404:339-344

Turner N, Heilbronn LK (2008) Is mitochondrial dysfunction a cause of insulin resistance? Trends Endocrinol Metab 19:324-330

van der Horst A, Burgering BM (2007) Stressing the role of FoxO proteins in lifespan and disease. Nat Rev Mol Cell Biol 8:440-450

Vasa-Nicotera M (2004) The new kid on the block: the unfolded protein response in the pathogenesis of atherosclerosis. Cell Death Differ 11(Suppl 1):S10-S11

Vellai T (2009) Autophagy genes and ageing. Cell Death Differ 16:94-102

Vellai T, Takacs-Vellai K, Zhang Y, Kovacs AL, Orosz L, Muller F (2003) Genetics: influence of TOR kinase on lifespan in $C$. elegans. Nature 426:620

Vittorini S, Paradiso C, Donati A, Cavallini G, Masini M, Gori Z, Pollera M, Bergamini E (1999) The age-related accumulation of protein carbonyl in rat liver correlates with the age-related decline in liver proteolytic activities. J Gerontol A Biol Sci Med Sci 54: B318-B323

Wallace DC (2005) A mitochondrial paradigm of metabolic and degenerative diseases, aging, and cancer: a dawn for evolutionary medicine. Annu Rev Genet 39:359-407
Wang XZ, Lawson B, Brewer JW, Zinszner H, Sanjay A, Mi LJ, Boorstein R, Kreibich G, Hendershot LM, Ron D (1996) Signals from the stressed endoplasmic reticulum induce C/EBP-homologous protein (CHOP/GADD153). Mol Cell Bio 16:4273-4280

Wang MC, Bohmann D, Jasper H (2005) JNK extends life span and limits growth by antagonizing cellular and organism-wide responses to insulin signaling. Cell 121:115-125

Wang L, Harris TE, Lawrence JC Jr (2008) Regulation of proline-rich Akt substrate of $40 \mathrm{kDa}$ (PRAS40) function by mammalian target of rapamycin complex 1 (mTORC1)-mediated phosphorylation. J Biol Chem 283:15619-15627

Wolff S, Dillin A (2006) The trifecta of aging in Caenorhabditis elegans. Exp Gerontol 41:894-903

Wolkow CA, Kimura KD, Lee MS, Ruvkun G (2000) Regulation of $C$. elegans life-span by insulinlike signaling in the nervous system. Science 290:147-150

Wullschleger S, Loewith R, Hall MN (2006) TOR signaling in growth and metabolism. Cell 124:471-484

Yamauchi T, Kadowaki T (2013) Adiponectin receptor as a key player in healthy longevity and obesity-related diseases. Cell Metab 17:185-196

Yang L, Li P, Fu S, Calay ES, Hotamisligil GS (2010) Defective hepatic autophagy in obesity promotes ER stress and causes insulin resistance. Cell Metab 11:467-478

Yoshida H (2007) ER stress and diseases. FEBS J 274:630-658

Youle RJ, Narendra DP (2011) Mechanisms of mitophagy. Nat Rev Mol Cell Biol 12:9-14

Yu L, McPhee CK, Zheng L, Mardones GA, Rong Y, Peng J, Mi N, Zhao Y, Liu Z, Wan F et al (2010) Termination of autophagy and reformation of lysosomes regulated by mTOR. Nature 465:942946

Yu Y, Yoon SO, Poulogiannis G, Yang Q, Ma XM, Villen J, Kubica N, Hoffman GR, Cantley LC, Gygi SP et al (2011) Phosphoproteomic analysis identifies Grb10 as an mTORC1 substrate that negatively regulates insulin signaling. Science 332:13221326

Zahn JM, Sonu R, Vogel H, Crane E, Mazan-Mamczarz K, Rabkin R, Davis RW, Becker KG, Owen AB, Kim SK (2006) Transcriptional profiling of aging in human muscle reveals a common aging signature. PLoS Genet 2:e115

Zhang Y, Goldman S, Baerga R, Zhao Y, Komatsu M, Jin S (2009) Adipose-specific deletion of autophagy-related gene 7 (atg7) in mice reveals a role in adipogenesis. Proc Natl Acad Sci USA 106:19860-19865

Zhao L, Ackerman SL (2006) Endoplasmic reticulum stress in health and disease. Curr Opin Cell Biol 18:444-452

Zhao J, Brault JJ, Schild A, Cao P, Sandri M, Schiaffino S, Lecker $\mathrm{SH}$, Goldberg AL (2007) FoxO3 coordinately activates protein degradation by the autophagic/lysosomal and proteasomal pathways in atrophying muscle cells. Cell Metab 6:472-483

Zhou L, Liu F (2010) Autophagy: roles in obesity-induced ER stress and adiponectin downregulation in adipocytes. Autophagy 6:1196-1197

Zhou L, Liu M, Zhang J, Chen H, Dong LQ, Liu F (2010) DsbA-L alleviates endoplasmic reticulum stress-induced adiponectin downregulation. Diabetes 59:2809-2816 
Zid BM, Rogers AN, Katewa SD, Vargas MA, Kolipinski MC, Lu TA, Benzer S, Kapahi P (2009) 4E-BP extends lifespan upon dietary restriction by enhancing mitochondrial activity in Drosophila. Cell 139:149-160

Zinszner H, Kuroda M, Wang X, Batchvarova N, Lightfoot RT, Remotti H, Stevens JL, Ron D (1998) CHOP is implicated in programmed cell death in response to impaired function of the endoplasmic reticulum. Genes Dev 12:982-995

Zoncu R, Efeyan A, Sabatini DM (2011) mTOR: from growth signal integration to cancer, diabetes and ageing. Nat Rev Mol Cell Biol 12:21-35 